\title{
Política y cultura de género en Nicaragua. Caso: Salvador Mendieta Cascante
}

\section{Claudia Morales Mairena ${ }^{1}$}

\section{Resumen $^{2}$}

Recepción: 16 de mayo de 2018 / Aceptación: 7 de agosto de 2018

La coyuntura histórico política de inicios del siglo XX en Nicaragua planteó retos mayúsculos en torno a las ciudadanías modélicas. El acento respecto a las ciudadanías estaba en los discursos sobre la moral y la castidad por los cuales corrió mucha tinta de manos de ilustres intelectuales nicaragüenses, entre ellos el líder unionista Salvador Mendieta Cascante. Este trabajo tiene por propósito analizar los discursos de intelectuales nicaragüenses, en especial de Mendieta sobre las construcciones ideales de género: femenino/masculino. Para ello, analizo sus diarios personales, exámenes morales y su obra más importante, La Enfermedad de Centroamérica.

\section{Palabras clave}

Ciudadanías; proyecto cultural; masculinidad; feminidad; Centroamérica

\section{Abstract}

The historical and political circumstances of the early 20th century in Nicaragua raised major challenges around ideas of model citizenship. The emphasis regarding citizenship came from the discourses on morality and chastity, of which much ink flowed from the hands of distinguished Nicaraguan intellectuals, among them the Unionist Salvador Mendieta Cascante. This work focuses on analysis the speeches of Nicaraguan intellectuals, especially Mendieta's about ideal gender construction: female/male. To do this, the article is mainly based on the analysis of personal diaries, moral exams, as well as his most important book, La Enfermedad de Centroamérica.

1 Nicaragüense. Licenciada en Sociología por la Universidad Centroamericana (UCA). Actualmente, es asistente de investigación en el Instituto de Historia de Nicaragua y Centroamérica (IHNCA) y en el Instituto Interdisciplinario de Ciencias Sociales (IICSS), ambos de la UCA. Correo electrónico: claudiamorales17@rocketmail.com

2 El presente artículo es fruto del programa de becas University Foundation for Development Cooperation (USOS) en convenio con la Universidad de Amberes de Bélgica y la UCA. El programa tiene el propósito de fortalecer las capacidades investigativas en jóvenes de la UCA. Agradezco a Juan Pablo Gómez, tutor de esta investigación, por su rigurosa revisión y sus aportes. También, agradezco a Myriam Rivas, directora del Archivo Histórico del INHCA-UCA, por su amable atención y por facilitarme la documentación requerida. Finalmente, a los investigadores del IHNCA, Ligia Peña y Antonio Monte, por sus lecturas y comentarios para mejorar este trabajo. A lo largo del proceso de desarrollo de esta investigación se han publicado varios avances. Ver Morales (2018). 


\section{Keywords}

Citizenship; cultural project; morality; chastity; Central America

\section{Resumo}

No começo do século XX na Nicarágua, a conjuntura histórico-política colocou grandes desafios em torno dos modelos de cidadanias. A ênfase com respeito às cidadanias estava nos discursos sobre a moral e a castidade, pelos quais muita tinta fluiu das mãos de ilustres intelectuais nicaraguenses, entre eles o líder sindicalista Salvador Mendieta Cascante. Este trabalho tem como propósito analisar os discursos de intelectuais nicaraguenses, em especial de Mendieta, sobre as construções ideais de gênero feminino/masculino. Para tanto, analisa-se seus diários pessoais, exames morais e sua obra mais importante La Enfermedad de Centroamérica.

\section{Palavras chave}

Cidadanias; projeto cultural; masculinidade; feminilidade; América Central

Salvador Mendieta Cascante (1879-1958) fue un destacado intelectual y político nicaragüense cuya prolífica obra da cuenta de problemáticas socioculturales significativas de Centroamérica en la primera mitad del siglo XX. Su trayectoria fue de carácter regional y, muy probablemente, el mayor hito al respecto fue la fundación del Partido Unionista Centroamericano (PUCA) en 1899, en la ciudad de Guatemala. El propósito con la creación de este partido político fue impulsar la integración centroamericana y tratar de cambiar la cultura política autoritaria que predominaba en los gobiernos de la región. A su parecer, los gobiernos liberales del siglo XIX, ya sea en su primera etapa a inicios de siglo o en las reformas de finales de este, privilegiaban el uso de la fuerza sobre el de la razón ${ }^{3}$. Según Margarita Silva, estudiosa de la obra de este intelectual, Francisco Morazán y Gerardo Barrios, cada uno representativo de las etapas del liberalismo decimonónico antes mencionadas, eran para Mendieta dos ejemplos de políticos autoritarios y caudillistas que gobernaron Centroamérica por el ímpetu (Silva, s. f, p. 22). En contraposición con esta cultura autoritarista, el político proponía la consolidación de un ejercicio democrático del poder. En consecuencia, el PUCA debía ser un instrumento para promover estos deseos de cambio.

Desde muy temprana edad, el líder unionista estudió en diferentes países de centroamericana, situación que le hizo interesarse por la integración de esta. Tengamos presente que el proyecto de la federación e integración centroamericana estuvo muy presente en el discurso político regional a lo largo del siglo XIX, como bien lo señala Arturo Taracena en el texto Historia

3 El primer período del liberalismo en Centroamérica se produjo a partir de 1821, después de la declaración de independencia de Centroamérica. El segundo período del liberalismo se produjo en el último cuarto del siglo XIX y las primeras décadas del XX. Para mayor detalle, consultar la conocida obra, Historia general de Centroamérica (Taracena, 1993, p. 167). 
política de Centroamérica (1995). Mendieta vivió en cada uno de los cinco estados en perpetua "trashumancia unionista", tal y como lo señala Warren Mory, uno de los estudiosos del proyecto unionista de este intelectual.

Entre las investigaciones realizadas sobre Mendieta se encuentran las de Juan Mendoza (1930), Thomas Karnes (1961) y Warren Mory (1999). Mención especial deben tener las investigaciones de Margarita Silva (s. f.) por sus alcances analíticos y minuciosidad. Aunque en otro artículo se analiza con mayor detenimiento los aportes de cada uno de estos autores ${ }^{4}$, señalo aquí que estas investigaciones se concentran en las siguientes temáticas:

a) biografía de Mendieta. Las investigaciones de carácter biográfico documentan eventos significativos de su vida en relación con acontecimientos históricos nacionales; b) su labor como político unionista. A pesar de su labor regional y transnacional, en estos estudios predomina un nacionalismo metodológico, asunto que resta importancia a la comprensión de su labor intelectual y política; c) el unionismo centroamericano como proyecto político que brinda valor a Mendieta como objeto de estudio en el marco de los esfuerzos unionistas de la región centroamericana, ya sea como punto de ruptura -con respecto a los esfuerzos decimonónicos- o como punto de continuidad de los mismos.

Reconozco los aportes de estos autores para el estudio de la figura y trayectoria política de Mendieta y, más en general, de los esfuerzos integracionistas en la historia de la región. No obstante, es otra la preocupación que motiva mi investigación: analizar cómo la política constituyó un terreno discursivo que forjó procesos configuradores de la personalidad. Mi apuesta es que el discurso político e intelectual interviene en la formación de la cultura de género. Por lo tanto, puede ser analizado como estrategia de poder orientada a la formación de subjetividades y modelos de masculinidad y feminidad. Visto así, Mendieta, más que un objeto de la historia política e intelectual, resulta un archivo cultural en el cual indagar acerca de las articulaciones antes mencionadas entre política, cultura de género y poder. Como veremos, en este trabajo se abarcaran dos campos problemáticos: el primero constituye las feminidades, sobre el cual se reflexiona la subordinación de las mujeres a la vida privada, al hogar y a los roles de madres y esposas abnegadas; mientras que el segundo se ancla en las masculinidades, específicamente en las de los varones profesionales y los jóvenes letrados destinados -a diferencia de las mujeres- a la vida y ciudadanía pública.

Para realizar el análisis se utilizan como recursos de investigación un acervo de diarios y exámenes morales resguardados por el Archivo Histórico del IHNCA-UCA, los cuales son una aplicación de admirable método orientada a educar la voluntad. Mendieta afirma que esta práctica de educar

$4 \quad$ Morales (2017). Hombres públicos, archivos íntimos: el fondo documental Salvador Mendieta (en adelante SMC). 
la voluntad inició con San Ignacio de Loyola (1491-1556), militar y religioso español. En sus palabras, "consiste en anotar las malas cualidades que se tienen y las buenas con las cuales se sustituirán” (Mendieta, 1934c, p. 221). Esta idea nace con la lectura que Mendieta hizo del libro Hombres de bien, de Benjamín Franklin, considerado uno de los Padres Fundadores de los Estados Unidos. Franklin vivió entre 1706 y 1790, su texto describe un plan para el desarrollo moral propio.

Además de los diarios y exámenes morales se utiliza la obra más conocida de Mendieta: La Enfermedad de Centroamérica (1934, dividida en tres tomos). En esta obra, el autor realza la educación pública y la instrucción cívico-política como vías de rescate de la decadencia con remedios políticos, sociales, económicos y morales. También, señala la importancia de la educación intelectual de hombres y mujeres. Para ilustrar mi argumento veamos la siguiente cita de dicho texto:

La escuela primaria de nuestra patria debe de ser una institución preparadora de hombres y mujeres sanos, fuertes, hermosos, buenos, aptos productores económicos, ciudadanos conscientes y activos y maestros de sí mismos en el decurso de la vida: en una palabra, seminario fecundo de perfectos caballeros y damas perfectas (1934c, p. 489).

Esta cita sirve para introducir el siguiente acápite que muestra cómo el discurso político parte de un perfeccionamiento de la raza que inicia por dejar en claro las posiciones y los roles según el género.

\section{Modelo femenino}

¿Qué discurso construye Mendieta en torno a lo femenino? ¿Qué estrategias prescribió en torno a la configuración de lo femenino? Encontramos respuestas a estas preguntas en la producción intelectual del nicaragüense dedicada a la "mujer centroamericana". Mi interés por analizar los discursos como estrategias de poder responde al registro documental en el cual el intelectual elaboró un discurso en torno a las ciudadanías modélicas del siglo XX. Me refiero a su conocido libro, ya mencionado, La enfermedad de Centroamérica, así como a sus diarios personales. En estos registros bibliográficos, él anotó su búsqueda del perfeccionamiento social y de género al hablar de la necesidad de contar con perfectos caballeros y damas también perfectas como muestra la cita de arriba. Veamos otro ejemplo, tomado de uno de sus cuadernos de viajes, registro en el que el autor documentó asuntos de su interés, fuera de Diriamba, su ciudad natal, como sus viajes a distintos países del mundo. En el Cuaderno de viaje No. 37, escribe: "La mujer nació para el hogar, para consagrarse toda entera a mitigar los dolores de su esposo en el viacrucis de la vida, para ser el polo magnético de una familia siempre hacia el rumbo de 171 una virtud" (1940, p. 7). 
En esta cita se dilucida el rol que Mendieta le asigna a la mujer centroamericana: una mujer dedicada completamente a la familia y al hogar, cuya función exclusiva es la domesticidad, la sujeción al marido y el sufrimiento como modo natural de vida. Al respecto de esto último subrayemos el imaginario de la cultura católica en el viacrucis, momento de la pasión y antesala de la crucifixión de Jesús. En sus estudios sobre la dominación masculina, Pierre Bourdieu expresa que existe una división de las cosas y de las actividades -sexuales o no-, de modo que la oposición entre lo masculino y lo femenino recibe su necesidad objetiva y subjetiva de su inserción en un sistema de oposiciones homólogas (1990, p. 20). En la cita que analizamos, al designar el rol "nació para el hogar", denota la división socialmente construida entre los sexos como naturales y contiene por ello una total afirmación de legitimidad (p. 21). Consecuentemente, se naturaliza que la mujer nació para el hogar y para el viacrucis de la vida. Con el apoyo de lo propuesto por Bourdieu (1990), se interpreta que el discurso de Mendieta funciona como una maquinaria simbólica que tiende a ratificar la dominación masculina en la que se apoya, materializándose en la delimitación de un espacio para la mujer.

Este discurso en torno a la mujer no era exclusivo de Mendieta. Da cuenta de un proyecto cultural socializado y reproducido a la manera de una conducta de dominación y posicionamiento de la mujer en el espacio de subordinación. El discurso enuncia que "el lugar" y posición de la mujer en la sociedad es el hogar. Como evidencia veamos un artículo de la revista de cultura católica Juventud, publicado en 1945 y titulado "Para ser madre te hizo Dios". Aunque el cuaderno de viaje de Mendieta es de 1911 y el artículo de Juventud de 1945, ambos nos sirven para ilustrar la división sexual del trabajo, esto es, lo que corresponde hacer al hombre y a la mujer en la vida:

Toda mujer tiene dentro de sí una madre. Es que Dios ha destinado a la mujer a ser la ayuda del hombre por medio de la maternidad ... Según la voluntad de Dios, el hombre es "el obrero del mundo". A él le corresponde ganar el sustento de la vida con su trabajo. Lo mismo sucede en el destino de la mujer, su oficio es ser madre; y este oficio ha de realizarlo unida al hombre por el matrimonio y a él sumisa (1945, p. 449).

Esta cita da cuenta del pensamiento que difundía la revista católica Juventud. Su propósito era formar un patrón de género. En el caso de las mujeres, como podemos ver, el género estaba encadenado a la cultura católica y a una postura de recogimiento y sumisión ante la autoridad de los hombres. A partir de lo anterior, considero que Mendieta describe a la mujer desde una visión católica, la mujer a los pies de la cruz. María sufre el viacrucis de su hijo Jesús hasta verlo morir, cumpliendo de esa manera con su rol de madre. En el pensamiento del autor está presente ese ideal católico conservador. Más adelante explicaré cómo estas aseveraciones son contradictorias en su pensamiento. 
La cita anterior de la revista Juventud es significativa para mi análisis puesto que, como mencioné, devela que la división sexual del trabajo y el discurso focalizado en la mujer no eran exclusivos de Mendieta. Correspondían a un discurso predominante en la época, es decir, a un proyecto cultural. La cultura católica era un atributo importante de dicho proyecto, compartido por intelectuales como Mendieta y los que publicaban en Juventud. Todos estos hombres letrados coincidían en la necesidad de evitar que las mujeres nicaragüenses, en especial las de la élite, cayeran en los vicios de la modernidad (Gobat, 2010, p. 315). Michel Gobat ha trabajado esto último en detalle en su libro Enfrentando el sueño americano (2010). En su trabajo, él pone especial atención a la lucha de la cultura católica contra la mujer moderna. La defensa de esta identidad católica se entiende como una forma de cohesión social. En el intento de construir una "imagen nacional" se estableció un ordenamiento político y cultural autoritario y tradicionalista bastante hostil y coercitivo, en especial por las connotaciones religiosas que emanaban de los discursos de los intelectuales, las restricciones y exclusiones con respecto a las mujeres.

Pero, ¿a quiénes beneficiaba este proyecto cultural? y ¿a quiénes estaba dirigido? Es evidente que la revista Juventud no fue pensada para la población nicaragüense en general. Si analizamos cada número de esta publicación, podemos constatar que sus portadas estaban adornadas por jóvenes católicos de la élite conservadora de Nicaragua. No era el ciudadano común, el indígena o el obrero. Eran jóvenes letrados, profesionales y ciudadanos distinguidos de la clase alta y media alta del país. Uno de los objetivos de Juventud era el apostolado, resumido en la aportación valiosísima de la Congregación Mariana a la perfección social. Los escritores de esta revista apostaban por dicha perfección a través de las enseñanzas morales y religiosas.

Como podemos notar, la religión se constituyó en un elemento cohesionador de la sociedad. Desde la perspectiva de los intelectuales conservadores de los años 20 del siglo pasado, daría solidez a la nacionalidad de Nicaragua, a su parecer amenazada por la intervención norteamericana y por la llegada de nuevas costumbres. Amenaza especial era "la mujer moderna". Como señala Gobat, esta era sinónimo de demandas feministas por mayores derechos políticos e independencia económica (2010, p. 325). También se hace evidente que, si bien Mendieta era anticlerical, como mencionaré en las páginas siguientes, en términos culturales no difería significativamente del pensamiento conservador. De hecho, en sus discursos sobre la mujer ideal, esta tenía claras características Marianas. Evelyn Stevens, en su investigación sobre "Marianismo: la otra cara del machismo en Latinoamérica" (1977), reflexionó sobre cómo el marianismo es un patrón de creencias y comportamientos centrados en la aceptación popular de un ideal de mujer caracterizado por tener cualidades de superioridad moral y fuerza espiritual. De tal modo que esta última genera abnegación, infinita capacidad de humildad y sacrificio (Stevens, 1977, p. 91). 
El análisis de Stevens encaja muy bien desde el pensamiento de Mendieta y el contexto histórico en el que se desarrolla. Sin embargo, el concepto de marianismo tiene ciertos límites que son señalados por Marysa Navarro (2002) en el texto Against Marianismo, donde desvela que este patrón no era un hecho profundamente arraigado en los rasgos culturales latinoamericanos, sino una variante del Victorianismo introducido en la segunda mitad del siglo XIX (p. 257). Por lo tanto, el culto a la mujer con atributos divinos no necesariamente es aplicable en todo el continente, lo que problematiza los marcos teóricos impuestos a los estudios de género en Latinoamérica. Pero basándome en las especificidades culturales e históricas de Nicaragua para la primera mitad de siglo XX, considero que puede ser aplicado aunque con precaución.

Evidente es que la mujer en la primera mitad del siglo XX era concebida por los intelectuales de entonces como otredad. Es decir, el otro en relación con el yo como un grupo social al que nosotros no pertenecemos, en este caso, las mujeres para los hombres (Todorov, 1987, p. 13). Al respecto, en su famoso libro El segundo sexo, Simone de Beauvoir (1949, p. 4) argumenta cómo ha sido interpretada la mujer a través de la historia humana: "La mujer se determina y se diferencia con relación al hombre, y no este con relación a ella; la mujer es lo inesencial frente a lo esencial. Él es el Sujeto, él es lo Absoluto; ella es lo Otro", ella es objeto desde la construcción social de lo femenino.

\section{¿Virtud femenina o complacencia masculina?}

Dentro de la misma línea de análisis sobre la subordinación femenina, cabe detenerse en la configuración de lo femenino como "virtud". En sus notas sobre la mujer centroamericana, Mendieta apunta: "La mujer centroamericana es, por lo general, de voluntad débil y de consiguiente carece de la energía necesaria para educar a los seres que reciban vida de ella" (1911, p. 1). Y, a la manera de una terapéutica, propone: "Mujeres: educad, vigorizad vuestra voluntad" (1911, p. 1). Como deja claro esta cita, Mendieta reproduce el discurso sobre la debilidad de la mujer. A la vez, implícitamente postula la fortaleza del hombre.

Este hecho me hace reflexionar que los defectos mencionados por Mendieta para caracterizar lo femenino no están inscritos en la naturaleza y tienen que estar construidos por un prolongado trabajo de socialización. Es decir, de diferenciación activa en relación con el sexo opuesto (Bourdieu, 1990, p. 67).

Otra forma de virtud femenina que Mendieta confiere a la mujer es una innata tendencia caritativa que debe orientarse hacia la solidaridad consciente, previsora cooperación y el fecundo altruismo. Como ya mencioné, en el discurso de Mendieta la mujer es un ser percibido como el otro, colocándola en una posición de debilidad, de servidumbre y que posee, como afirma Friedrich Nietzsche en su obra La genealogía de la moral (1887), únicamente valores 
"blandos". No obstante, la feminidad de la que habla Mendieta se fundamenta en una forma de complacencia respecto a las expectativas masculinas.

Para analizar este modelo de mujer virtuosa, revisemos el ideal de mujer centroamericana que Mendieta proponía en sus notas para impartir clases de historia de Centroamérica, titulado "Episodio de Rafaela Herrera":

Rafaela Herrera mujer representativa de Centroamérica: el hecho estupendo de aquella niña heroína comparable a la Juana de Arco de Francia produjo el más grande regocijo y el más legítimo orgullo en todo el reino de Guatemala, y es desde entonces uno de los hechos que solidarizan de modo indestructible al pueblo centroamericano (Mendieta, s. f., p. 1).

Rafaela Herrera era hija de un español, el capitán de artillería Josef de Herrera. Se dice que nació en Cartagena, posiblemente entre 1740 y 1743. Aquí podemos ver que el modelo ideal de mujer propuesto por Mendieta se articula con el proyecto racialista y eugenésico que se llevó a cabo en toda Centroamérica durante la década de 1920. Es decir, el patrón de género está también articulado a un patrón racial. Según Marta Elena Casaús, "los intelectuales centroamericanos no fueron capaces de pensar en un proyecto de nación racialmente homogénea por la vía del mestizaje. En su lugar prefirieron blanquear la nación e invisibilizar al indio y al afrodescendiente" (2014, p. 99). Para el caso concreto de Nicaragua, Jeffrey L. Gould explica que el mito de la "Nicaragua mestiza", nació en la época de la rebelión indígena de 1881. Ese mito, en su primera etapa, pintó la derrota indígena como victoria de la "civilización" sobre la "barbarie". Desde entonces, el discurso oficial ha descrito insistentemente a Nicaragua como un país étnicamente homogéneo (Gould, 1997, p. 15). De acuerdo con Gould "el mito ha 'blanqueado' el paisaje social y ha impregnado las raíces de la cultura política nicaragüense con la sustancia de sentido común, transmitido de generación en generación” (1997, p. 18).

Herrera, como mujer extranjera y española, no solo representa a la mujer virtuosa centroamericana y al blanqueamiento racial. También encaja maravillosamente con la virgen María porque colabora con la salvación de la patria y además tiene sangre española. De esa manera, ella se acerca al linaje de sangre y mujer pura que cultiva su virtud a través de la costumbre, el hábito y el ejercicio, porque la virtud, según Aristóteles, es una disposición adquirida de la voluntad. Veamos lo que afirma Mendieta al respecto en sus escritos Ruta para mantener mi voluntad triunfadora (s. f.): "El catolicismo da a la voluntad el tributo de la misericordia o caridad, y personifica esa cualidad en Jesús; y especialmente en María" (Mendieta, s. f., p. 2). Como podemos apreciar, Mendieta no solo confiere a la mujer ideal esas cualidades de misericordia, abnegación y sufrimiento, sino que se cruza a un plano antropológico, biológico y genético, teniendo una concepción propia de los colonizadores y en especial de los españoles conquistadores. 
De acuerdo con la agenda de investigación del IHNCA-UCA, sigo las líneas de trabajo del investigador Juan Pablo Gómez, quien desarrolla la construcción de ciudadanías en los años treinta y cuarenta del siglo pasado. Su trabajo me ayuda a comprender que la ruta genealógica del ideal de mujer nicaragüense da cuenta de la articulación entre género, identidades geo-culturales y pasados coloniales (Gómez, 2015, p. 182). Especial consideración para el presente trabajo tiene uno de los casos analizados por este investigador. Me refiero al intelectual nicaragüense Pablo Antonio Cuadra (1912-2002). En sus artículos publicados en la revista Juventud, Cuadra redactó artículos sobre mujeres nicaragüenses y resaltó en ellas que España trajo a Nicaragua el tipo de mujer española, castiza y ejemplar, es decir, el tipo de mujer mariana (Cuadra [1922], citado por Gómez, 2015, p. 22).

En la primera mitad del siglo XX, los intelectuales hispanistas -Cuadra entre ellos- simpatizaban y tenían un gran aprecio y amor hacia España. Mendieta no era la excepción al respecto. Veámoslo en detalle en esta cita:

Quien escribe este libro es un amador fervoroso de España y de todo lo español: entiendo que el más altivo anglosajón no tiene por su raza el orgullo y la satisfacción honda y firme que tengo yo por el pedazo de neto españolismo que corresponde en la genealogía del pueblo centroamericano. Era un adolescente de 15 años cuando noté por primera vez este poderoso e invencible amor mío por la madre patria y a la raza que la puebla (1934a, p. 35).

Los círculos letrados consideraban como mujer ideal y representativa de Centroamérica a Rafaela Herrera por ser de sangre española, por haber sido instruida según las exigencias de su época como una joven con ardiente amor a la patria. Es importante señalar que el líder unionista representa un recurso significativo para estudiar comparativamente los discursos de los intelectuales centroamericanos en torno al perfeccionamiento y blanqueamiento de la raza. En este sentido, Mendieta resulta de particular interés por disentir en su propuesta del ideal de mujer católica. Veamos un ejemplo tomado del tercer tomo de su libro La Enfermedad de Centroamérica:

Las centinelas avanzadas del fanatismo y la intransigencia son las niñas católicas de las clases ricas... su edad es muy indefinible, pudiendo adjudicársele así treinta y cinco, como cincuenta y cinco años, solterona biliosa tiene en la cara las señales todas del celibato obligado y del mal humor consiguiente, es por lo general enteca y de cuerpo un poco inclinado hacia delante. Viste con descuido, segura que su reino no es de este mundo y despide por todo perfume de almizcle y alcanfor. Cúbrase cuidadosamente la cabeza con un tapado de lana negro o café.

La hembra ésta asiste todos los días a la iglesia, en la cual desempeña dos o tres empleos, confiesa hasta fatigar a los reverendos, hace guerra obstinada y sin cuartel a cuantos no cumplen los deberes del más refinado católico y fuma de continuo cigarrillos largos de papel (Mendieta, 1934c, p. 68).

En este tomo, Mendieta describe al "sujeto enfermo", galería de la que forma parte la mujer, como podemos ver. A su parecer, el modelo de mujer que describe con cuidadoso afán antropológico era parte de los problemas 
que aquejaban a la región y no permitían su desarrollo ni civilización. Quiero detenerme en analizar el uso que Mendieta le da al término "hembra". Es un uso bastante peyorativo, no porque esté relacionado a la naturaleza, al reino animal, sino porque, siguiendo a Beauvoir, la confina en su sexo. Es decir, la mujer es percibida como una matriz, un ovario, una "hembra". Y si este sexo le parece al hombre despreciable y enemigo hasta en las bestias inocentes, ello se debe, evidentemente, a la inquieta hostilidad que en él suscita la mujer. Sin embargo, quiere encontrar en la biología una justificación a ese sentimiento (1934a, p. 12). Desde una perspectiva antropológica, llamar a una mujer hembra, como expresa David Le Breton, "es reducir el cuerpo a simple artefacto, es vaciarlo de significación simbólica y de valor" (Le Breton, 1993, p. 5).

El término "hembra" también denota fragilidad porque es claramente individualizada de los "machos". Este último, en lugar de ser peyorativo, es sinónimo de orgullo, fuerza y virilidad. Diagnósticos como el recién citado abundan en el fondo documental de Mendieta que se encuentra en el IHNCAUCA. Ello da cuenta del potencial de este archivo para analizar el discurso que este intelectual, conocido más por su labor unionista, elaboró en las primeras décadas del siglo XX, y las epistemes desde las cuales mira su sociedad y las ciudadanías de género. Estas temáticas de investigación dan seguimiento a problemáticas antes desarrolladas por investigadores como Antonio Esgueva y Frances Kinloch ${ }^{5}$. Ambos han publicado extensamente sobre los procesos de formación del Estado-nación y la cultura política, asuntos fundamentales para investigar sobre historia intelectual y ciudadanías de género.

Antes también llamé la atención sobre la importancia de realizar una comparación de la labor intelectual. Quiero retomar esta idea para señalar que, a diferencia de otros intelectuales nicaragüenses, como Pablo Antonio Cuadra (1912-2002), José Coronel Urtecho (1906-1994) y Joaquín Pasos (1914-1947), Mendieta tenía una particularidad. Si bien creía en la existencia de un ser supremo, era anticlerical, y criticaba fuertemente a la Iglesia católica. Era miembro activo de la logia masónica de Nicaragua. Warren Mory da constancia de ello en las siguientes líneas:

Si bien Mendieta nació y creció en un ambiente católico, nunca prestó atención a las prácticas externas de esa religión. Aunque no fue antirreligioso, si [sic] se puede decir que fue anticlerical. Mendieta consideraba al clero como uno de los enemigos de la unión centroamericana (1999, p. 25).

Es importante tener en cuenta que los masones creen en la divinidad. Tradicionalmente se les asociaba como enemigos de la Iglesia católica porque ellos basaban sus principios en la libertad, igualdad, fraternidad, mismos principios que impulsaron la Revolución francesa. Mendieta era un libertador, por eso no es raro que perteneciera a la logia masónica, ni que 
fuese anticlerical sin renunciar a la doctrina básica del catolicismo -Dios, oración, penitencia, sacrificio, control de la mujer-. El problema con la Iglesia católica es que había sido una institución dominante por siglos y los masones querían la libertad religiosa.

Ser masón era inaceptable para muchos herederos de los Caballeros Católicos, oligarcas conservadores de Granada con una influencia de pensamiento social católico (Gobat, 2010, p. 316). Entre los herederos de esta tradición se encuentran los intelectuales ya mencionados, Pablo Antonio Cuadra, José Coronel Urtecho y especialmente Joaquín Pasos. Este último publicó un artículo sobre los peligros de la masonería en Azul y Blanca, una revista de cultura católica dirigida especialmente a mujeres. Para Pasos, Ios masones eran enemigos que debían exterminarse en defensa del catolicismo, porque el fin de la masonería era la demolición definitiva de dicha religión. Leamos sus palabras al respecto:

La logia masónica en Nicaragua trabaja fieramente para la abolición del nombre de Dios, por la enseñanza laica y por el desprestigio de la iglesia. El fin principal que persiguen las logias en nuestro país: hacer decisiva su influencia en los destinos de Nicaragua. La laicización e internacionalización de la sociedad es uno de los objetivos de la masonería (Pasos, 1939, p. 14).

Las palabras de Pasos son útiles para comprender la razón por la cual Mendieta clasifica a la mujer católica como no ideal, sino como "sujeto enfermo", porque su postura de mujer fanática siempre fue criticada de inculta y, por lo tanto, debía de educársele con mayor esmero y cultivar en ellas las virtudes sociales del valor del trabajo, la solidaridad, cooperación, altruismo, caridad y amor (Mendieta, 1934c, p. 225).

Subrayo nuevamente la utilidad comparativa que propicia el archivo de Mendieta para prácticas académicas como la historia intelectual y cultural. La cultura católica se convierte en un elemento fundamental para comprender el pensamiento político de estos intelectuales. Por un lado, los Caballeros Católicos estaban en contra de una sociedad laica. Por otro, los masones estaban a favor de esta porque desde la época colonial, la Iglesia católica tenía el control social. Sin embargo, encontramos muchas similitudes entre los herederos de los Caballeros Católicos y pensadores anticlericales, como Mendieta. Ejemplo de ello es el discurso racial en torno al elemento étnico que debía prevalecer en Centroamérica. Según Mendieta, el elemento étnico que debía predominar en la formación del tipo centroamericano era la raza blanca. Leamos como ejemplo la siguiente cita:

¿Cuál debe de ser el elemento étnico que predomine en la formación del tipo centroamericano? Es la raza blanca la que debe dar el mayor y mejor contingente para la formación del futuro tipo étnico centroamericano, al cual deberán dar también sus mejores cualidades las razas cobrizas y negras, pero subordinadas a las superiores de la blanca (Mendieta, 1934a, p. 25). 
Es evidente el sistema de pensamiento que predominaba en la primera mitad del siglo XX. Como antes mencioné, investigadoras de redes intelectuales centroamericanas, como Casaús, alegan que el racismo y la eugenesia generaron un consenso ideológico en la mayoría de los pensadores de la época. A partir de las palabras de Mendieta podemos ver la manera en que había calado el ideal de raza blanca considerado lo superior y horizonte aspiracional. Por su parte, estaba lo negro e indio, eso que no debía seguirse reproduciendo. El desprecio por lo mestizo era evidente por parte de los intelectuales.

Para comprender a Mendieta como parte de un ambiente de ideas, vale la pena comparar su cita con las propuestas que sobre esta temática elaboró Pablo Antonio Cuadra, quien niega la posibilidad de que la mujer indígena o esclava sea considerada digno ejemplo de la feminidad nicaragüense. Según Cuadra, estas identidades no respondían al concepto civilizado de mujer. Pertenecían, a su parecer, a la prehistoria de la feminidad. Sin duda, aquí es evidente una operación retórica gracias a la cual la conquista es el punto cero de la historia y este punto es crucial para comprender el discurso racial de este intelectual y la no contemporaneidad de la mujer indígena en el mismo. Para Cuadra, la mujer "precolombina" es la masa que Dios ha predestinado para que en ella opere la labor hispana cristianizadora y surja un nuevo mundo femenino orientado hacia el gran tipo de mujer de la Historia cristiana: la Virgen María madre de Dios (citado en Gómez, 2015, p. 182).

De esta manera se puede observar que Mendieta y Cuadra coincidían en su discurso racial. Promovían estrategias en torno al blanqueamiento y "mejoramiento de la raza centroamericana", para decirlo con las mismas palabras de nuestro autor. Inclusive, no hay diferencia en el discurso de lo católico como estrategia moralizadora. Este punto es muy importante y vale la pena detenerse en él. En la posición anticlerical de Mendieta existe una aporía: las cualidades de la mujer ideal -pura, casta, servil, entregada al hogar, al esposo y a sus hijos-son las mismas cualidades de la mujer católica. Mendieta se proyecta públicamente con una cultura política anticlerical. Sin embargo, al estudiar detenidamente su producción intelectual, se desnuda como defensor de la cultura de género católica-tradicional.

Las virtudes femeninas antes mencionadas son parte del pensamiento mariano, proyecto cultural que Mendieta tiene muy arraigado, aun y si públicamente se maneja con un discurso anticlerical. María es el modelo de la mujer católica. Es siempre virgen, esclava del señor; obedece sus palabras, educa a su hijo y llora a su lado. Por eso es que Mendieta en este aspecto no rompe con el pensamiento de Cuadra y Joaquín Pasos, pues continuó reproduciendo el mismo modelo propuesto por ellos. Su concepción cultural, religiosa, y la práctica espiritual que llevaba de sí mismo no sufrió alteraciones. Por muy subversivo que se presentó en la discusión pública con los ideales de la Iglesia católica, su discurso intelectual legitimó 
los mismos ideales tradicionales de dominación en la forma más arcaica y primitiva del patriarcado.

\section{Metáforas: "la plaza" como violencia simbólica}

Tocar en todas partes donde sea posible y no sea prohibido, y ahondar donde el terreno se halle propicio. Señalando los turnos según la mayor o menor cercanía a obtener la posesión de la plaza, que siempre deberá ser virgen (Mendieta, 1926, p. 15).

La frase con la que inicia este acápite fue escrita por Mendieta en un manual titulado Vademecum de Vida Integral. Me detengo en dos metáforas redactadas por él. Primero estudio la metáfora de "la plaza" feminizada, de la que hace mención en el texto antes mencionado. Para ello me apoyo en la definición de feminización que lleana Rodríguez analiza en su libro Hombres de empresa, saber y poder en Centroamérica (2011). En su análisis, la autora argumenta lo siguiente:

Feminización es el traslado de los conjuntos conceptuales definitorios de género de un espacio de conocimiento a otro, en este caso de lo femenino a lo nacionalgeográfico. Las tecnologías de represión que delatan estas transferencias son el empequeñecimiento, la desproporción en el juicio, el abuso en el trato, el adueñamiento de las geografías y el ninguneo de las costumbres (Rodríguez, 2011, p. 38).

En la cita de Mendieta antes expuesta, es obvio que se refiere al proceder sexual con féminas, otorgándole una metáfora de "plaza que siempre deberá ser virgen" iniciadas por él sexualmente y en consecuencia apropiadas. Apoyándome en Rodríguez, analizo el uso de las metáforas para referirse a la mujer como un espacio geográfico, empequeñeciendo a la figura femenina y adueñándose de ese espacio que designa como algo que debe y puede obtenerse. Notemos también cómo a través de la posesión de "la plaza" el hombre reafirma su "ser".

Al respecto, Beauvoir expresa que la idea de posesión es siempre imposible de realizar positivamente. En verdad, nunca se tiene nada ni a nadie, por tanto, uno intenta cumplirlo de un modo negativo. La manera más segura de afirmar que un bien es mío, consiste en impedirle a otro que lo use, nada parece al hombre más deseable que aquello que jamás ha pertenecido a ningún ser humano: entonces la conquista se presenta como un acontecimiento único y absoluto (1949, p. 80).

Mendieta explícitamente se posiciona como un explorador de tierras vírgenes, tierras nunca antes exploradas y penetradas porque eso es lo que hace fascinante a un espacio geográfico, saber que se puede dominar ese espacio, ese objeto. Siguiendo a Beauvoir, "si este espacio ya fue dominado o explorado por otro hombre, este ha perdido sus más profundas virtudes: 
porque hay más promesas en el agua no domada de los torrentes que en la de las fuentes públicas" (1949, p. 81).

Desde la perspectiva de Mendieta, la plaza siempre debía tener la característica de "virgen". Interpreto sus palabras desde la concepción biológica del sujeto: "Al romper el himen, el hombre posee el cuerpo femenino, en esa operación irreversible hace del mismo, sin equívocos, un objeto pasivo, afirma su toma de él" (Beauvoir, 1949, p. 81). De esa manera, el hombre conquista y descubre ese espacio geográfico y satisface así su deseo sexual.

Pongo atención en la metáfora de los espacios que nos explica perfectamente Celia Amorós por medio del concepto "topos" como lugar común, lugar de todos, como ámbito transaccional en tanto es la tierra de nadie. Es decir, describe bien la metáfora de la "plaza" como un lugar público que es de todos y es de nadie a la vez, un espacio que puede ser manoseado, violentado. Este topos es la "mujer", ese lugar constituido como lugar prácticosimbólico (Amorós, 1990, p. 43).

Quiero volver a la cita de Mendieta con la que inicié este acápite, específicamente en el extracto que dice, "ahondar donde el terreno se halle propicio". Me interesa la manera en que da cuenta de la mujer como espacio incomprendido, en este caso, "terreno propicio". Según Amorós, la mujer es tierra de nadie, pues se ha desterritorializado respecto al ámbito privado acotado por un varón. Y, por tanto, es ámbito de disponibilidad sexual virtualmente para todos. Por consiguiente, la mujer está siempre pre interpretada sin importar la lógica situacional (Amorós, 1990, p. 44). De acuerdo con la dialéctica hegeliana, esto sería una relación entre amo y esclavo, en la que se da una negación del otro, de reconocerlo como sujeto. En este caso, es una negación de interpretar al otro, pues según la lógica patriarcal "con las mujeres ya se sabe".

Debido a lo anterior, hay una íntima relación entre violencia e interpretación porque la ideología patriarcal es el no pensamiento hacia la mujer (Amorós, 1990, p. 45). Al parecer, Mendieta viene a fortalecer esta feminización de la plaza como espacio geográfico, lugar desterritorializado. Siguiendo a Rodríguez, esta lectura genera una figura de abuso, rapto y violación, representado en una violencia simbólica hacia la mujer ${ }^{6}$.

En cuanto a metáforas, como modo de violencia simbólica, existen muchas en los Diarios de Meditaciones Unionistas, pero en este artículo solo analizo la siguiente metáfora encontrada en uno de ellos que llamó mi atención: "Dulcinea del Toboso es la más hermosa mujer del mundo, aunque yo fuera el más desgraciado caballero de la tierra" (1954, p. 38).

6 El efecto de la dominación simbólica (trátese de etnia, de sexo, de cultura, de lengua, etc.) no se produce en la lógica pura de las conciencias conocedoras, sino a través de los esquemas de percepción, de apreciación y de acción que constituyen los hábitos y que sustentan, antes que las decisiones de la conciencia y de los controles de la voluntad, una relación de conocimiento profundamente oscura para ella misma (Bourdieu, 1990, p. 54). 
Dulcinea del Toboso es un personaje ficticio en la obra Don Quijote de la Mancha de Miguel de Cervantes. Mujer que el Quijote idealizó, pero que también, a lo largo de la obra, ridiculizó. Analizo esta metáfora a partir del texto La Emperatriz del Mundo, escrita en 1916 por Aurelio Baig, quien hace un estudio de este personaje incorpóreo. Según Baig, Cervantes creó dos Dulcineas en contraposición una con la otra: la ideal es una labradora, modelo de imprecación amorosa. La otra es, cuando Sancho conoce su nombre real, la que motiva burlas (p. 13). Es decir, una que tiene aspecto hombruno, de baja clase, de innoble ademán y la otra radiante, mujer bella y femenina. Cuando Mendieta escribió "Dulcinea del Toboso es la más hermosa mujer del mundo, aunque yo fuera el más desgraciado caballero de la tierra", se encontraba en un dilema. Tuvo amores no correspondidos y es por ello que considero que ve a la mujer en dos momentos: la mujer amada que ve como compañera ideal para casarse y la mujer que no le corresponde su amor y que la ve con desdén por este hecho, y procede a satirizarla. Leamos lo siguiente:

Resuelto como estoy a no escribir de nuevo a Piquetillo y a no visitarla, me sorprende que ahora haya estado pensando en ella. Se ve que ella nada sexual quiere conmigo; y por eso me extraña que mi pensamiento se ocupe de su persona (Mendieta, 1955, p. 45).

Como podemos ver, Mendieta constantemente estaba presignificando a la mujer. En sus diarios no hay indicios que hablara de frente con ellas y les dijera sus sentimientos. Siempre las estaba interpretando a priori y haciendo sus propias conjeturas. Tal como lo explica Amorós, probablemente para Mendieta el significar a la mujer a priori era algo común, puesto que con las mujeres "ya se sabe" o "nunca se sabe". En este sentido, es una violencia simbólica al margen de la coacción física debido a que esta última no es la única forma de violencia.

Otra forma que considero violencia simbólica hacia las mujeres es el hecho de verlas como mercancía intercambiable o simples cuerpos que pueden ser desechados a la brevedad. Al respecto, Mendieta expresa lo siguiente: "Lo divertido es que las dos me gustan, sin que la una excluya a la otra, lo ideal sería tenerlas a las dos y lo más ideal sería tenerlas esporádicamente" (Mendieta, 1955, p. 46).

En esta cita se devela el uso de la mujer como un objeto desechable que luego de cada idilio se pueda cambiar por otra. De acuerdo con Bourdieu, la dominación masculina que convierte a las mujeres en objetos simbólicos, cuyo ser (esse) es un ser percibido (percipi), tiene el efecto de colocarlas en un estado permanente de inseguridad corporal o, mejor dicho, de dependencia simbólica (1990, p. 86).

En resumen, a la mujer desde esta perspectiva presignificada se le ha desterritorializado, no es comprendida como sujeto, sino que se le ha cosificado y se le ha determinado como "el otro" a través del discurso escrito. Los intelectuales de la primera mitad de siglo XX legitimaron el rol 
femenino como un rol de madre, mujer de hogar, mujer sufrida, otredad, objeto simbólico, reduciendo su vida y sus aspiraciones únicas y exclusivamente al ámbito privado. Nacional y regionalmente, este discurso intelectual y político se corresponde con la negación de ciudadanía y derechos políticos a las mujeres centroamericanas en las normativas constitucionales y electorales desde la post independencia hasta pasada la primera mitad de dicho siglo. También está ligado a un sistema cultural que tiene sus orígenes en la Revolución francesa y la tendencia Jacobina, inspirada por Rousseau, quien enfatizaba que la mujer como madre es una institución, la ubre simbólica depositaria y transmisora de las virtudes cívicas, pero a la misma vez negaba sus derechos políticos. A la mujer se le niegan sus derechos políticos y ciudadanos, pero su misión es cultivar buenos ciudadanos y velar desde el espacio privado para que se cumplan las condiciones éticas en el ámbito de lo público (Amorós, 1990, p. 51). La mujer está confinada solamente a la familia, donde el hombre gobierna como padre y esposo, porque se pensaba que la mujer era incapaz de gobernar, incluso del gobierno doméstico; ella solo administra y aconseja a los hijos, los instruye para ser ciudadanos ejemplares.

\section{Masculinidades}

Serviréis a vuestra patria, eligiendo hombres doctos que enseñen a vuestros hijos, hombres sabios para gobernar vuestro pueblo, hombres de honor y responsabilidad que administren los bienes comunes, escogiendo siempre hombres de ciencia y de prudencia a quienes asociarse para vuestros negocios y aún vuestro trato (Rodas, 1943, p. 20).

Empiezo la segunda parte de este trabajo con una cita del libro, Mis prisiones y peregrinaciones por Centroamérica en aras del ideal unionista (1943), de Joaquín Rodas. En dicha cita podemos ver cómo la educación, el trabajo letrado y la tarea de gobernar se deposita en los hombres, algo sintomático del modelo de masculinidad que apuntaban como ideal intelectuales como Mendieta. Los varones profesionales constituyeron el tipo ideal de ciudadano centroamericano, ubicándolo en la esfera de la vida pública. Principalmente como poseedores del saber, virtud y moral como pilar de una ciudadanía centroamericana, basada en el amor a la patria grande; jóvenes tomadores de decisiones organizados en sociedades varoniles. Ejemplo de ello es la Sociedad el Derecho, fundada en 1899 en Guatemala y de la que el mismo Mendieta formó parte. Estaba conformada por jóvenes capitalizadores de riquezas materiales a través del trabajo, con una estrecha relación con la voluntad y la castidad. Leamos su descripción de ciudadano ideal en la siguiente cita de La Enfermedad de Centroamérica:

Existen honrados y enérgicos estudiantes que aman con sinceridad a Centroamérica, se preocupan por el positivo bienestar de estos pueblos, creen en el bien y en la justicia y trabajan por el implantamiento de una nueva política que sustituya a la infecunda y corrompida del día de hoy. Se reúnen en asociaciones, inician trabajos de verdadera utilidad, estudian al país y a sus propiedades 
intrínsecas, sostienen con firmeza los choques con los gobiernos caciquiles y, a pesar del hostil medio ambiente y del estrecho y oscuro horizonte que se presenta aquí a los hombres de carácter, persevera en su obra, demostrando que todavía hay rectas intenciones y voluntad fuerte (1934b, p. 42).

Es evidente que los criterios del ideal masculino son el hombre letrado, héroe, patriota que se sentía responsable de la fundación de las repúblicas y de sus más caras instituciones: academias, universidades, asociaciones, liceos, entre otras. Observamos una preeminencia del sujeto del saber como sujeto a imitar. El espacio que Mendieta le confiere al hombre es la vida pública, su participación como ciudadano tiene un peso mayor que el de la mujer. Para ilustrar sigamos analizando sus palabras:

La mujer que sabe gobernarse a sí misma no tiene ningún inconveniente en ser ciudadano; pero que sus atenciones especiales como hija, esposa, o madre la retienen especialmente en el hogar, de modo que su padre, su esposo, sus hermanos o sus hijos, bien pueden desempeñar estas ocupaciones mientras ellas cuidan de la casa (Mendieta, 1964, p. 39).

Con respecto a esta cita que aparece en el Tratado de Educación Centroamericana, vemos que Mendieta hace una división sexual de las actividades: hombre igual a sujeto público; mujer igual a sujeto de la vida privada (hogar). Beauvoir provee elementos analíticos que respaldan cómo se encuentra constituido el trabajo doméstico al que está dedicada la mujer, que parece ser el único conciliable con las cargas de la maternidad, la confinan en la repetición y la inmanencia; son faenas que se reproducen día tras día, bajo una forma idéntica que se perpetúa casi sin cambio; no produce nada nuevo (Beauvoir, 1949, p. 28).

El caso de los hombres es muy distinto. Siendo de la vida pública, los hombres se plantean fines y metas. Trabajan para conservar el mundo dado, construyen los cimientos de un nuevo porvenir. Como ya mencioné, es por ello que los jóvenes letrados se creen responsables de la fundación de las repúblicas y el bienestar de su patria, porque resulta que el poder político siempre ha estado en manos de los hombres, tal y como LéviStrauss afirma al final de su estudio sobre las sociedades primitivas: "La autoridad pública o simplemente social pertenece siempre a los hombres" (Strauss, 1949, p. 83).

De suma importancia para Mendieta era que el joven centroamericano, como sujeto público, además de tener metas profesionales, económicas y familiares en su vida, también cuidara celosamente de su cuerpo y sus energías. Para ello proponía como modelos a seguir a los griegos y a los estadounidenses. Sabemos que los griegos concebían la vida como una obra de arte. Por ello se examinaban a sí mismos y eran poseedores de una moral cívica como trabajo artístico, no por creencias religiosas ni por penitencia. Copio íntegramente las palabras de Mendieta sobre los griegos: 
Como los griegos de los buenos tiempos y como los estadounidenses de hoy, debe el centroamericano tener un culto respetuoso y constante por su cuerpo y sus energías corporales: consagrar diariamente una parte de su tiempo a los juegos y deportes vigorizantes y virilizadores (Mendieta, 1934c, p. 44).

Esta cita nos brinda otra dimensión analítica importante en la investigación de las intersecciones entre política y cultura de género. La categoría de cuerpo es central para el análisis de la política y la sociedad; en concreto, para el estudio de la configuración de ciudadanías de género y masculinidades. Mendieta expresa su simpatía ante estos modelos - griegos y estadounidenses-. Para él, eran los ideales que debían imitar los centroamericanos. Me detengo a analizar sus palabras valiéndome del concepto de virilidad de Bourdieu, quien me ayuda a contextualizar su definición dentro de un plano carismático. Por lo general, entendemos la virilidad como esa capacidad de reproducción sexual y social, pero de acuerdo con el contexto que nos presenta Mendieta, se comprende como una actitud de buscar la gloria, el reconocimiento y aceptación en la esfera pública y este reconocimiento se cristaliza en el deporte que contiene cualidades viriles (Bourdieu, 1949, p. 69).

De acuerdo con los exámenes morales de Mendieta, para ser digno y enérgico, el modelo masculino centroamericano debía guardar una estrecha relación con su voluntad y castidad. Pongamos atención que, para Mendieta, a diferencia de otros intelectuales nicaragüenses de su época, como Cuadra, la castidad no era cuestión de religión sino de ciencia. Era importante porque trascendía al encauzamiento y dominio de su cuerpo, de sí mismo; era un culto a la disciplina y la higiene. Por esta razón, el joven debía de mantener pleno control de su mente y su cuerpo para mantenerse viril y enérgico:

En el hombre, y en mí tiene estrecha relación la voluntad con la castidad, con el ejercicio físico, con el estado de la atmósfera, con el estado de salud y de ánimo. No he hallado alimento especial que la prolongue y la mantenga; pero hay ejercicios y cambios que me la despiertan o me la vigorizan; por ejemplo, andar a caballo, pasear temprano en la mañana, en las montañas, en el campo en el mar; las relaciones sexuales cuando he tenido algún periodo de continencia, viajar; ayunar de vez en cuando; proponerme un ciclo metódico de cierto y determinado tiempo. En cambio me la debilitan los excesos sexuales, el exceso de comida, el desvelo, el calor, la falta de baño, la excesiva permanencia en un solo lugar (Mendieta, s. f., p. 2).

Para Mendieta era muy importante como hombre de bien que el centroamericano se estudiase asimismo (siguiendo la lógica de San Ignacio de Loyola, seguido por Benjamín Franklin), como él bien expresó en su Cuaderno de Meditaciones No. 36: "recogerse como el erizo" para vigorizar la voluntad (1940, p. 38). Los hombres centroamericanos, especialmente, debían examinarse a diario, por medio de los Exámenes Morales, para perfilar las buenas y malas costumbres. Esto es algo que también podemos encontrar en La Enfermedad de Centroamérica. De manera que cuando 
alcancen la mayoría de edad tendrán rigurosamente establecida esa benéfica costumbre (Mendieta, 1934b, p. 222)7.

En este manuscrito titulado Ruta para mantener mi voluntad triunfadora (s. f.), Mendieta se proponía alimentar de acuerdo con una lista de prácticas rigurosas una voluntad triunfadora, para ser un hombre de éxito, triunfador. Si la voluntad es alimentada por la continencia sexual, entonces considero que él estaba haciendo referencia a una práctica ascética tomada de la vida religiosa católica, llevada a cabo por los griegos como una forma de arte. Inclusive, hacía énfasis en llevar una vida disciplinada y ética que es un estilo de vida que, como ya mencioné en el apartado anterior, la promovían los masones. Pero lo interesante es que también tenía modelos de vigorosa voluntad. A continuación muestro algunos ejemplos del manuscrito antes mencionado, subrayando esas voluntades por el mismo Mendieta. Uno de ellos era Francisco Pizarro, el conquistador español, y otro Don Quijote de la Mancha:

Hay dos tipos de voluntad que se deben de tener presente siempre, ambas españolas, ambas mayores de cincuenta años y ambas igualmente resultadas a triunfar: el uno es el luchador que llamo pragmático, o sea conocedor del ambiente que le rodea, de los remedios con que cuenta, de las dificultades que confrontará, es Pizarro. El otro es el luchador romántico, desconocedor del ambiente que le rodea, de los medios de que dispone, de los obstáculos que le saltan al paso, es Don Quijote. Este en el ridículo, mientras que aquel es respetado, temido y admirado (Mendieta, s. f., pp. 7-8)8.

De esta cita analizo únicamente el caso de Francisco Pizarro para explicar las rutas genealógicas del ideal masculino. Antes llamo la atención a que me encuentro con una similitud más con uno de los herederos de los Caballeros Católicos: Pablo Antonio Cuadra y Salvador Mendieta. Notemos que el ideal masculino es también producto de un proyecto cultural propio de la primera mitad del siglo XX que tenía el propósito de formar caballeros virtuosos y letrados. De acuerdo con Gómez, Pizarro reúne tres características masculinas fundamentales para la buena gobernancia: conquistador, gobernador y encomendero. Pizarro fue encomendero en Panamá antes de ser conquistador en el Perú y posteriormente, fue gobernador de la Nueva Castilla (2015, p. 110).

Para Cuadra, la figura de Pizarro es representación de un pasado imperial, como símbolo de la esperanza de un proyecto venidero. De la misma manera, para Mendieta, la figura de Pizarro es el modelo a seguir para tener una voluntad triunfadora. Es decir, un hombre que debe de ser respetado, pero a la vez, temido y admirado, un hombre que conoce lo que le rodea. Claramente, se ve que Cuadra y Mendieta tenían como "rutas genealógicas de autoridad la figura del hombre poderoso que maneja con firmeza y a la vez con amor; con

7 La Enfermedad de Centroamérica, tomo I.

8 Las palabras "pragmático" y "romántico" están subrayadas originalmente por Mendieta en su manuscrito. 
la fuerza de la espada pero también de la cruz; con dominio del cálculo pero sin ceder en la pasión" (Gómez, 2015, p. 112).

En síntesis, ¿cuál es la genealogía de ideal masculino según este intelectual? Para Mendieta, los referentes de masculinidad se encuentran en los griegos como adoradores del arte corporal, del cuidado de sí. Otro modelo son los estadounidenses representados por Franklin y todo su sistema de examinación moral para ser un "hombre de bien". Finalmente, la raíz de esta genealogía se encuentra en San Ignacio de Loyola, militar y religioso español que educaba la voluntad también a través de la examinación ${ }^{9}$. Y con Francisco Pizarro, hombre de voluntad recia, firme, hombre triunfador. Mendieta era gran admirador de los españoles y los describía como la identidad geopolítica a la que debía aspirar el ciudadano centroamericano. Claro es que esta consideración tiene una connotación racista, respecto al blanqueamiento de la raza centroamericana. Como ejemplo de ello, leamos esta cita de registro cotidiano, encontrada en uno de sus diarios de meditaciones unionistas: "La incomprensible marca de español que llevo por doquier. Al comprar hoy un sombrero de fieltro, el tiendero me preguntó bruscamente que si soy español. Le dije que sí, y me dijo que él también se consideraba español, porque es judío sefardita" (Mendieta, 1955, p. 55).

En esta cita, Mendieta deja entrever que, al igual que Cuadra, encuentra sus virtudes en la gobernancia representada por Pizarro y su estatuto de autoridad. Ellos no se sentían representados por virtudes propias centroamericanas. De hecho, Mendieta no se sentía centroamericano, su sentir era de una raza imperial con un registro genealógico europeo. Leamos sus propias palabras como evidencia: "me siento tan distinto a esta gente centroamericana, desmoralizada y parasitaria que temo por mi [sic] y por mis hijos"10. Esta es una perspectiva de alguien que mira su sociedad desde afuera y desde arriba, como bien lo ha señalado lleana Rodríguez para el caso del intelectual salvadoreño Salarrué, quien en sus cuentos ejemplifica rasgos de brutalidad y atraso en los indios, poniendo así distancia entre él como sujeto y los indios. Pongamos atención que esta perspectiva de reducir y ningunear no solo era propia de Mendieta sino que era muy común entre algunos intelectuales centroamericanos (Rodríguez, 2011, p. 187).

En las palabras de Mendieta es evidente el desprecio hacia la cultura originaria, hacia lo nacional. A lo largo de su obra más conocida, La Enfermedad de Centroamérica, caracteriza al centroamericano como un sujeto atrasado, sucio, bruto, nervioso, entre otras características peyorativas

$9 \quad$ El Examen es una práctica espiritual anterior a san Ignacio y no exclusiva de la tradición cristiana. Encontramos diferentes formas de examen, con acentos espirituales o morales distintos, en los pitagóricos y en los estoicos, en Sócrates, Séneca.

10 Diario de Meditaciones Unionistas. San Salvador/ Guatemala 1934-1940. 
que dejan claro que el sujeto representativo de la región centroamericana no es construido a partir de las ciudadanías indígenas o mestizas, sino del europeo y blanco, identidad geocultural con la que proponía mejorar la raza, como ya mencioné. Como podemos ver hasta aquí, Mendieta es un caso de análisis que revela las estructuras ideológicas y sentimentales relacionadas con la política centroamericana y la cultura de género en la primera mitad del siglo XX.

\section{Castidad como virtud moral}

Porque hubo un tiempo de mi adolescencia en que ardí en deseos de hartarme de las cosas más bajas, y osé oscurecerme con varios y sombríos amores, y se marchitó mi hermosura, y me volví podredumbre ante tus ojos por agradarme a mí y desear agradar a los ojos de los hombres

(San Agustín, [Las Confesiones], 1957, p. 11).

Tanta abstinencia, tanto dominio sobre mí mismo, tanta virtud ¿para qué me ha servido? Para vivir en la más angustiosa miseria de levita

(Mendieta, 1940, p. 1821).

En el presente apartado analizo el discurso de Mendieta respecto a la castidad como virtud moral. Para estudiar la virtud moral masculina utilizo una cita del libro Las Confesiones, de San Agustín. La cita de arriba muestra un arrepentimiento de acciones pasadas basadas en la lujuria y el alimento de los deseos de la carne que lo apartaron de Dios. Para San Agustín, la influencia del pensamiento maniqueo y platónico consideraba el deseo sexual como algo pecaminoso, por la violencia y vergüenza que acompañaba tal acto. De ahí que la única finalidad de la sexualidad era la reproducción, pensamiento que llega a prevalecer aún en el siglo XX.

En el discurso de Mendieta, la castidad o continencia sexual, como él lo llama, "es en el orden biológico lo que el ahorro en lo económico. Sin este ningún capital se forma o se sostiene" (Mendieta, 1934c, p. 44). El discurso de Mendieta coincide con la cultura católica de la época. Revistas católicas como Juventud y Azul y blanco, por ejemplo, eran un medio de difusión escrito en el que algunos intelectuales llamaban a las y los jóvenes a ser castos para agradar a Dios y para tener un cuerpo sano, puro y limpio de enfermedades venéreas. En 1943, Alfonso Junco dijo lo siguiente:

Es, en cambio, patente el estrago que en la salud consuman los descarríos sexuales. Agotamiento prematuro, desajustes nerviosos, enfermedades inmundas, lacras hereditarias (Junco, 1943, p. 8).

Aquí leemos el discurso de Alfonso Junco, escritor mexicano, conocido defensor del franquismo, de la religión católica y del hispanismo imperialista. Junco abogó por la restauración del imperio español en América. También fue director de la muy conocida revista de cultura mexicana antimodernista y procatólica titulada Ábside (Gómez, 2015, p. 172). 
Al respecto de la lujuria Mendieta menciona: "Es la lujuria defecto nacional y racial del centroamericano y una de las causas de la enervante abulia que le condena a la inacción, al atraso o la servidumbre" (Mendieta, 1934a, p. 44). Notemos que Mendieta racializa la lujuria tal como lo menciona Casaús para los casos de Guatemala y EI Salvador. El racismo de las élites políticas a menudo giraba en torno a las nociones del indígena como sucio, degenerado y como impedimento para el progreso (Casaús, 2014, p. 93).

En las citas que acabamos de leer, Junco y Mendieta escriben sobre los efectos que causaban el no ser casto y hacer mal uso de su cuerpo y su sexualidad. Para propósitos de este artículo no ahondaré sobre la castidad como higiene corporal, pero sí es de mi interés ilustrar la preocupación de estos intelectuales por la higiene corporal y moral. Para explicar el sentido de la castidad en el siglo XX, como virtud moral, utilizo las teorías de Foucault quien, retomando las palabras de Platón, dice que el deseo nace del alma, porque lo que se desea es una representación del recuerdo de lo que da placer. De ahí concluye que no puede haber deseo más que en el alma, lo cual parece constituir para los griegos, de acuerdo al orden sexual, el objeto de la reflexión moral y no exactamente el propio acto (Foucault, 2002, p. 42).

Es debido a ello que Foucault se plantea la siguiente pregunta: "¿con qué fuerza nos dejamos llevar por los placeres y los deseos?" Refiere a la fuerza que asocia entre sí los actos, placeres y deseos, realizado en lo que él llama "el grano de la experiencia ética" de la aphrodisea ${ }^{11}$ (2007, p. 42). Veamos que dentro de la moral lo que distingue a unos hombres de otros no es tanto el tipo de objeto hacia lo que se orientan, ni el modo de práctica sexual. Es, ante todo, la intensidad de dicha práctica. El autor explica que la separación está entre la moderación y la incontinencia.

De tal manera, siguiendo a Foucault es importante para el análisis moral del sujeto indicar si, en su práctica con las mujeres, ha sabido dar pruebas de mesura. En este sentido, la inmoralidad de los placeres del sexo es siempre del orden de la exageración, la demasía y el exceso (Foucault, 2007, p. 44). Esta es la explicación que nos lleva a considerar la importancia del auto examen en los exámenes morales de Mendieta. Él tomaba nota en su diario "Educación de la voluntad" de la cantidad de veces que tenía relaciones sexuales y las anotaba como "falta en castidad". Atribuía muchas veces su deseo sexual al insomnio, preocupaciones y falta de ejercicio físico. El mismo Mendieta dice: "No tuve el suficiente dominio sobre mí mismo para abstenerme de gozar del amor. Me he propuesto extirpar de raíz pensamientos lascivos" (1910, p. 3).

En el libro Genealogía de la moral, Friedrich Nietzsche expresa que "todo artista sabe que en estados de tensión, y preocupación espiritual, el dormir 
con mujeres produce un efecto muy nocivo porque consume la fuerza" (1887, p. 148). A la luz de esta interpretación de Nietzsche, podemos constatar que efectivamente Mendieta, al permanecer en un estado sedentario, de insomnio o saciedad, experimentaba fuertes deseos sexuales que luego terminaban con sus fuerzas. A su parecer, ello debía ser, continuamente, objeto de autoexamen. En sus exámenes morales se encuentra un registro diario y riguroso sobre las faltas en castidad y en sus exámenes podemos constatar que había días en los que tenía una práctica sexual hasta de dos veces por día durante cinco días seguidos a la semana. Encuentro aquí una relación entre castidad o vigor genésico, como él solía llamarlo, y vigor físico. Exactamente cuando no tenía actividad física, como realizar gimnasia sueca, él llevaba a cabo actividades sexuales.

La castidad en Mendieta también estaba relacionada con el insomnio. En el cuaderno "Educación de la Voluntad" (Ejercicios Diarios) escribió: "falta en vigor genésico y vigor físico: el estado intermedio entre la vigilia y el sueño es muy peligroso, porque he notado entonces una singular debilidad volitiva. En ese estado cometí la falta en vigor genésico" (1910, p. 10).

Debido a la falta de abstinencia, Mendieta se auto castigaba para tener una conducta irreprochable y no dejar llevarse por los placeres del sexo. Leamos la siguiente cita: "Como el punto flaco de mi naturaleza es la lujuria, en castigo de no haberme sabido dominar anoche no tendré pensamientos ni acto alguno sensual hasta el 10 de noviembre próximo, inclusive" (1917, p. 8).

Es respecto a la variable cuantitativa del acto sexual que Foucault nos explica "que en el dominio del comportamiento sexual la apreciación moral no sería trazada a partir de la naturaleza del acto, sino a partir de la actividad y de sus gradaciones cuantitativas" (2002, p. 45). Por esta razón, Mendieta se examinaba diariamente en sus exámenes morales para llevar cuenta de cuántas faltas tenía en castidad y poder detectar en qué estaba fallando. Expresa el objetivo de estos exámenes morales en su Cuaderno No.7:

Constatar mi conducta diaria para conseguir que sea irreprochable como la de un perfecto caballero, y desde los puntos de vista físico, moral, económico, intelectual y estético, de manera que mi vida sea una realización constante de la justicia, la verdad, el bien, el amor y la belleza (1924, p. 4).

Como podemos notar en esta cita, Mendieta, además de ser un productor de enunciados en torno a la configuración del 'perfecto caballero', es un claro ejemplo de alguien que autorreguló su voluntad con base en el mismo discurso político. Es al mismo tiempo enunciador y sujeto de enunciado. Las detalladas anotaciones en sus cuadernos morales dan cuenta de un sujeto en permanente configuración a la luz de un conjunto de normativas destinadas a regular su cuerpo, género y estructura sentimental. Podemos caracterizar la examinación diaria que contienen los exámenes morales como un trabajo de constante introspección en la búsqueda del yo que 
se encuentra en lo más profundo de su intimidad. El potencial que brindan los exámenes morales es muy amplio y rico en cuanto a la información de las virtudes por evaluar diariamente. Es un registro de progreso, retraso o constancia en las virtudes evaluadas. El objetivo es mejorar las virtudes que no se poseen a través de este registro diario de sus cuadernos. Esta capacidad de reflexión, de introspección, permite que el investigador o investigadora interrogue al autor y comprenda cómo se representa en la experiencia íntima del lenguaje.

Las líneas anteriores me llevan a reflexionar en el concepto de gobierno de sí, de Foucault. El gobierno en Foucault es gobierno de los hombres en su mixtura, con su riqueza, los recursos, los medios de subsistencia y los elementos propios del territorio. Es gobierno de los hombres en conexión con los usos, costumbres, modos de hacer y de pensar. Para Mendieta, era importante gobernarse él mismo, tener dominio sobre sí. Julián Sauquillo, en su libro Michel Foucault: Una Filosofía de la Acción (1989), nos explica que mientras en la interpretación cristiana de gobierno la conducción es colectiva, y se dirige a la vigilancia y moralización constante de sus miembros, en el gobierno individual es diferente.

En la persona que profesa el cristianismo hay una unión entre el pastor y los miembros del rebaño, pero esta unión es de sumisión e individualización personal. La pastoral cristiana despliega una serie de técnicas cristianas de examen, confesión y dirección de conciencia encaminadas a la mortificación y control de la carne en este mundo ${ }^{12}$. En la moral griega, de la que Mendieta era buen conocedor, no se da mortificación y sacrificio del individuo, sino gobierno racional de las pasiones (Sauquillo, 1989, p. 357). Un ejemplo encontrado en el Cuaderno de Virtudes de Mendieta dice: "Vigor genésico: uso moderadamente de los placeres genésicos, y solo para tener hijos o evitar enfermedades: se casto en pensamientos, palabras y actos"13.

El primer imperativo del gobierno de sí mismo, de acuerdo con el discurso de Mendieta, encontrado en su Cuaderno de Virtudes, debe ser el uso moderado de los placeres. Es decir, se cumple la teoría que analiza Foucault en cuanto a la variable cuantitativa del acto sexual, y el segundo imperativo que nos muestra la cita es que solo debe realizarse con el objetivo de procrear hijos o evitar enfermedades. Pero entonces, de no realizarse este auto examen por una tradición cristiana, lo hace por un trabajo artístico. Citando a Foucault, Sauquillo sostiene lo siguiente: "La moral antigua no posee un contenido normalizante, tal como ocurre en la moral cristiana, sino estético: a través de una elección personal los

12 El pecado, que es el término que usa el sacerdote en su interpretación de la "mala conciencia" animal (la crueldad dirigida hacia uno mismo), ha sido hasta hoy el mayor suceso de la historia del alma enferma. En el pecado hallamos la estratagema más nociva y peligrosa de la interpretación religiosa (Nietzsche, 1887, p. 183).

13 Cuaderno de Virtudes. El Salvador, 1918.

Cuadernos Inter.c.a.mbio sobre Centroamérica y el Caribe, Vol. 15, No. 2, octubre 2018-marzo 2019, 168-198 https://revistas.ucr.ac.cr/index.php/intercambio / DOI: https://doi.org/10.15517/c.a..v15i2.34647 
individuos libres eligen determinado comportamiento que pueda ofrecerles recuerdos de una vida bella" (1989, p. 372).

Es en este sentido, la constitución griega del sujeto moral no se realiza mediante un código de prescripciones, sino a través de una "estética de la existencia". Tal como lo hacía Mendieta: "estoy frente a mí mismo, para pensar, para meditar, para examinarme. Es la hora en la que me recojo sobre mí mismo" (1963, p. 51) ${ }^{14}$. Para Mendieta era una cuestión de arte, de cuido. La cuestión moral, como lo expresa Foucault, será la de saber cómo enfrentar esta fuerza, cómo dominarla y asegurar su conveniente economía. Es la reestructuración de las formas de relación con uno mismo y una transformación de las prácticas y técnicas sobre las que esta relación se apoya. A eso Foucault le llama enkrateia (Foucault, 2007, p. 62) ${ }^{15}$.

Hasta aquí hemos visto que la castidad, como virtud moral, era una preocupación para intelectuales como Mendieta, tanto en el discurso público a través de la cultura escrita de su libro La Enfermedad de Centroamérica, como en la escritura diarística íntima y privada, donde tenía un diálogo consigo mismo en un espacio textual que le confiere un conocimiento de sí. Es importante tomar en cuenta cómo este discurso de castidad funcionó como mecanismo de control social. De acuerdo con el tomo tres de La Enfermedad de Centroamérica, titulado Terapéutica (1934c), existe una estrecha relación entre control social y educación de la voluntad de los infantes desde recién nacidos. Para Mendieta, la educación de la voluntad era una responsabilidad de los padres de familia, especialmente de la madre. La naturalización del espacio doméstico y de la ternura como elementos naturalmente pertenecientes a la madre, eran dos criterios de los que se servía Mendieta para poner el peso de la educación sobre la mujer. Tal como lo asevera la cultura de salud pública que estimuló significativamente la maternidad, aspecto que desarrolla muy bien la investigación de Ligia Peña (2016). Copio a continuación un extracto de su trabajo:

En el caso de Nicaragua, el primer manual que circuló, Lecciones de Higiene del profesor Marcos Ortega, pone especial cuidado en enseñarle a las futuras madres cómo debía ser alimentado el recién nacido, el aseo diario, el mobiliario y el aseo del cuarto del bebé, la posición al acostarlo en la cuna para evitar el peligro de la asfixia a causa del vómito. Especial cuidado debía tener la madre con los órganos de la vista y el oído del recién nacido (Peña, 2016, p. 80).

Peña destaca que los textos para el cuidado de los bebés eran escritos por médicos varones, no precisamente involucrados con el cuido de los niños. Era "natural" y legítimo que el cuido de los niños fuese una tarea

14 Diario de Meditaciones Unionistas. El Salvador 15 de agosto 1963.

15 En la lengua clásica se utiliza para designar esta forma de relación con uno mismo, esa "actitud" necesaria a la moral de los placeres y que se manifiesta en el buen uso que de ella se hace. Se caracteriza por una forma activa del dominio de sí mismo (Foucault, p. 62). 
femenina. Peña alude a esta naturalización de la maternidad como un asunto de cultura de salud pública (2016, p. 80).

Desde la respectiva de Mendieta, la madre ejerce un control e influencia sobre el niño mucho mayor al del padre (1934c, p. 199). Ilustro con mayor detalle mi afirmación con la siguiente cita:

Los pensamientos se agolpan en la cabeza del hombre y de la mujer iberoamericanos en turbamulta indisciplinada, sobre todo en los habitantes de las ciudades populosas. De ahí la necesidad de que el padre y la madre de familia se acostumbren por diarios y repetidos esfuerzos a ejercer dominios sobre sus pensamientos, clasificándolos en orden de importancia u oportunidad, desechando todo pensamiento inútil y sobreponiéndose a toda impresión o impulso hasta que se mantenga la mente de ordinario como el lago tranquilo (1934c, p. 200).

En esta cita demuestro que la educación de la voluntad es un proceso que debe iniciarse desde que el niño o la niña nace, para convertir en un hábito el dominio propio. Esta acción no es únicamente responsabilidad de la familia, sino que depende de otras instituciones como la escuela y la iglesia. La función de estas instituciones, de acuerdo con Mendieta, era "combatir malas cualidades y cultivar las buenas" (1934c, p. 199). Un aspecto que Mendieta consideraba de suma importancia en cuanto a la necesidad de tener muy bien entrenada la voluntad, era la castidad. Al respecto, Gómez citando a Amorós expresa que "el fantasma regulador" de la castidad opera sobre el cuerpo y deja de constituir un asunto religioso y pasa a entrar en los dominios de la razón y de la salud (2015, p. 173). Es decir, la castidad no era practicada por Mendieta por razones religiosas, sino por razones de disciplina e higiene.

\section{Conclusiones}

El discurso sobre las ciudadanías modélicas en Centro América parte de un perfeccionamiento de la raza que inicia por dejar en claro las posiciones y los roles según el género. En el caso de las mujeres se develó que estas estaban confinadas a la vida privada, el hogar, al rol de madre, mujer sumisa y esposas abnegadas. Si bien podían tener una participación política en la sociedad, era más importante que se encargaran de los asuntos del hogar. Luego, se analizó el uso recurrente de metáforas en sus diarios para desentrañar las formas de violencia simbólica hacia las féminas, de tal manera que se demuestra de qué manera Mendieta, al igual que otros intelectuales de la época, le asignaban a la mujer el lugar del "otro", cosificándola, negándole derechos, presignificándola y posicionando a la mujer en una situación de debilidad y desventaja. Se le describía como un lugar público a través de la metáfora de "la plaza" que es de todos y de nadie a la vez; un espacio que puede ser manoseado, violentado. La plaza es la mujer constituida como lugar práctico-simbólico. 
Porsu parte, elideal masculino estabarepresentadoporvarones profesionales, jóvenes letrados. Los hombres estaban destinados a la vida pública porque como poseedores del saber eran pilar de la ciudadanía centroamericana. Los modelos masculinos no solo debían ser jóvenes estudiados. También debían ser hombres poseedores de virtudes morales y para ello era necesario abstenerse de algunas actividades perjudiciales para el cuerpo y la mente.

En las siguientes partes de este artículo se explicó mediante las teorías de Michel Foucault, la relación entre castidad y moralidad y se demostró que estas se encuentran íntimamente ligadas al uso mesurable de los placeres, no en el acto en sí. Es decir, lo inmoral está en la frecuencia con que se realiza el acto sexual, esto en la época significó un mecanismo de control social, porque Mendieta recomendaba examinarse a sí mismo diariamente para tener una conducta y una moral irreprochable y entre las virtudes que se auto examinaba estaba la castidad.

Estos discursos resaltan que los modelos a imitar tienen un registro genealógico europeo y se hace explícito y evidente un menosprecio hacia la cultura indígena esa a la que no se debe aspirar a ser. Mendieta y otros intelectuales, al igual que Cuadra, dejaron en claro que el elemento étnico que debía predominar era la raza blanca. En el caso de Cuadra, expresó que la india precolombina no podía ser ejemplo ni tipo de galería en la feminidad nicaragüense. En este sentido y sobre estas bases ideológicas y culturales se fortaleció el desprecio por lo originario y la exaltación y admiración hacia lo europeo a tal punto de tener modelos específicos a imitar.

\section{Referencias}

\section{Fuentes primarias}

Instituto de Historia de Nicaragua y Centroamérica-IHNCA, Archivo Histórico, Managua, Nicaragua. Documentos textuales, Fondo Documental Salvador Mendieta Cascante.

Azul y Blanca. Revista de la Acción Católica de Granada, Nicaragua. Año I- 1 de mayo 1939. Tip. El Centroamericano. No. 5. El peligro masónico por Joaquín Cuadra Pasos, 5-7.

Azul y Blanca. Revista de la Acción Católica de Granada, Nicaragua 1 de marzo de 1939 No. 3 Cristo y la Mujer, 25-27.

Cuaderno de Virtudes. El Salvador, (1918).

Cuaderno de Meditaciones Unionistas No. 36, (1940).

Cuaderno de Notas de Viaje No. 37. Guatemala, (17 de noviembre de 1940).

Cuaderno de Meditaciones Unionistas. Guatemala, (1954). 
Diario de Meditaciones Unionistas. San Salvador / Guatemala (1934-1940).

Diario de Meditaciones Unionistas. Guatemala, (1955).

Diario de Meditaciones Unionistas. El Salvador, 15 de agosto (1963).

Examen moral, Diario No. 4, sin lugar, (1917).

Examen Moral, Cuaderno No. 7, (1924).

Memento Permanente. Managua, Nicaragua, (1946).

Notas del Diario Íntimo del Dr. Mendieta, "Educación de la voluntad", (1910).

Notas de Salvador Mendieta sobre la mujer centroamericana, (1911).

Notas del Dr. Mendieta para impartir la clase de Historia de Centroamérica, "Episodio de Rafaela Herrera" y "Episodio de Nelson", (s. f.).

Ruta para mantener mi voluntad triunfadora, (s. f.). Revista Juventud, Congregación Mariana de Jóvenes Varones, Jalteva Granada Nicaragua, revista mensual con censura eclesiástica, año I- 8 de febrero 1943- No.2. Junco, Alfonso. pp. 6-9.

Revista Juventud, año I- mayo-junio de 1943 - Numero 6-7. Pablo Antonio Cuadra: sección galería de mujeres nicaragüenses pp. 25-28.

Revista Juventud, año III- febrero de 1945 - Número 26. Los extremos se tocan. Sección: para vosotras muchachas pp. 342-343.

Revista Juventud, año III- marzo 1945 - Número 27. La misión de la mujer. Sección: para vosotras muchachas. E. Ensiso V., pp. 363-364.

Revista Juventud, año III- junio 1945. Número. 30. Para ser madre te hizo Dios. pp. 448-450.

Vademécum de Vida Integral. Cartago, octubre (1926).

\section{Fuentes secundarias}

Amorós, Celia. (1990). Violencia y Sociedad Patriarcal. Madrid: Editorial Pablo Iglesias.

Baig, Aurelio. (1916). La emperatriz del mundo: estudio sobre Dulcinea del Toboso. Madrid: Biblioteca de España y América.

Bourdieu, Pierre. (1990). La dominación Masculina. Barcelona: Editorial Anagrama.

Beauvoir, Simone. (1949). El segundo sexo. Recuperado de http://users.dsic. upv.es/ pperis/El\%20segundo\%20sexo.pdf 
Casaús, Marta Elena. (2014). El mito impensable del mestizaje en América Central: ¿Una falacia o un deseo frustrado de las élites intelectuales? Anuario de Estudios Centroamericanos, 40, 77-113. Recuperado de https://revistas.ucr.ac.cr/index.php/anuario/article/view/16631/16134

Esgueva, Antonio. (2011). Elecciones, reelecciones y conflictos en Nicaragua, 1821-1963. Managua: Instituto de Historia de Nicaragua y Centroamérica(IHNCA) Universidad Centroamericana (UCA).

Foucault, Michel. (2002). La Historia de la Sexualidad I-La voluntad de saber. Argentina: Siglo XXI Editores.

Foucault, Michel. (2007). La Historia de la Sexualidad II-El uso de los placeres. Argentina: Siglo XXI Editores.

Mendieta, Salvador. (1964). Tratado de Educación Cívica Centroamericana. Managua: Talleres Nacionales.

Mendieta, Salvador. (1934a). La Enfermedad de Centroamérica. Descripción del sujeto y síntomas de la enfermedad. Tomo I. Madrid: Tipografía Maucci.

Mendieta, Salvador. (1934b). La Enfermedad de Centroamérica. Diagnóstico y orígenes de la dolencia. Tomo II. Barcelona: Tipografía Maucci.

Mendieta, Salvador. (1934c). La Enfermedad de Centroamérica. Terapéutica. Tomo III. Barcelona: Tipografía Maucci.

Mendoza, Juan. (1930). Salvador. Mendieta Biografía. Guatemala: Tipografía Sánchez y Deguise.

Morales, Claudia. (2017). Hombres públicos, archivos íntimos: el fondo documental Salvador Mendieta Cascante (Artículo inédito).

Morales, Claudia. (2018). Ciudadanía y masculinidad en la Nicaragua de la primera mitad del siglo XX. Caso de estudio: Salvador Mendieta Cascante. Recuperado de: http://istmo.denison.edu/n34/proyectos/04.html

Mory, Warren. (1999). Salvador Mendieta: Escritor y apóstol de la Unión Centroamericana. Birmingham, Alabama: Birmingham Southern College.

Le Breton, David. (1993). La carne. Usos médicos y mundanos del cuerpo humano. París: Métailié.

Gobat, Michael. (2010). Enfrentando el sueño americano: Nicaragua bajo el dominio imperial de Estados Unidos. Managua: IHNCA-UCA.

Gómez, Juan Pablo. (2015). Autoridad/Cuerpo/Nación- Batallas Culturales en Nicaragua (1930-1943). Managua: IHNCA-UCA. 
Gould, Jeffrey. (1997). El mito de "la Nicaragua mestiza" y la resistencia indígena, 1880-1980. San José: Universidad de Costa Rica.

Junco, Alfonso. (1943). La viril castidad. Juventud (Congregación Mariana de Jóvenes Varones, Jalteva-Granada Nicaragua), I(2), 6-9.

Karnes, Thomas. (1961). Los Fracasos de la Unión. San José: Instituto Centroamericano de Administración Pública (ICAP).

Kinloch, Frances. (2015). El imaginario del canal y la nación cosmopolita. Managua: IHNCA-UCA.

Navarro, Marysa. (2002). Against Marianismo. Gender's Place. New York. Macmillan.

Nietzsche, Friedrich. (1887). La Genealogía de la Moral. Madrid: Edimat.

Peña, Ligia. (2016). Medicina y política: Cultura de higiene y medicalización social en Nicaragua (1915-1928). (Tesis de Maestría). Managua: Universidad Centroamericana. Inédito.

Rodas, Joaquín. (1943). Mis prisiones y peregrinaciones por Centroamérica en aras del ideal unionista. Guatemala: Tipografía Nacional.

Rodríguez, lleana. (2011). Hombre de Empresa, sabery poderen Centroamérica. Managua: IHNCA-UCA.

San Agustín. (1957). Confesiones. Barcelona: Editorial Iberia.

Sauquillo, Julián. (1989). Michel Foucault: Una filosofía de la acción. Madrid: Centro de Estudios Continentales.

Silva, Margarita. (s. f.). Salvador Mendieta y la unión centroamericana (1879-1958). Recuperado de http://shial.colmex.mx/textos/Salvador_Mendieta_1.pdf

Stevens, Evelyn. (1977). Marianismo: La otra cara del machismo en Latinoamérica. En Ann Pescatelo (Ed.), Hembra y macho en Latinoamérica: Ensayos. México: Editorial Diana.

Strauss. Levi. (1949). Las estructuras elementales del parentesco. Madrid: Paidós.

Taracena, Arturo. (1993). Liberalismo y poder político en Centroamérica (1870-1929). Historia general de Centroamérica. (Tomo IV). (pp. 167-254) Madrid: Facultad Latinoamericana de Ciencias Sociales.

Taracena, Arturo. (1995). Historia política de Centroamérica (1821-1930). En Margarita Vannini (Ed.). Encuentros con la historia. (pp. 145-176). Managua: IHNCA-UCA. 
Todorov, Tzvetan. (1987). La conquista de América: el problema del otro. México D. F.: Siglo XXI Editores. 